\title{
Body apps \\ iPads for undergrad Anatomy and Physiology students
}

W

ould iPads with anatomy and physiology apps increase student learning in a small campus classroom? A campus librarian and a biology instructor at Penn State University certainly hoped they would. The Penn State Hazleton C a m p u s L i b r a ry and Department of Biology purchased iPads that were pre$1 \mathrm{o} \mathrm{a} \mathrm{d} \mathrm{e} \mathrm{d}$ with anatomy and physiology apps for the undergraduate

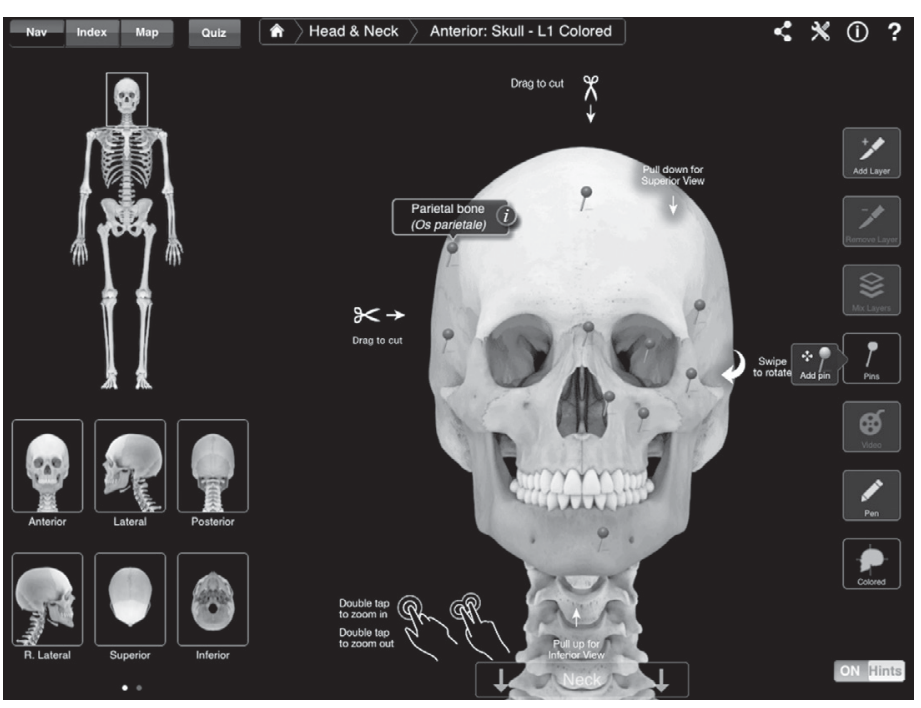

Screenshot of the 3D Medical: Skeleton System Pro III app. View this article online for detailed images. the health sciences field for a variety of purposes. ${ }^{1-5}$ Practicing health professionals use them in the clinical setting for patient care purposes, while undergraduate health scienc- anatomy and physiology curricula. During the first week of class, students received instruction about the use of library electronic resources related to anatomy and physiology. Students used the iPads in the classroom/ lab and borrowed them from the library to complete course assignments and study for exams.

\section{Getting started}

iPads and iPad apps are increasingly used in my laboratory "aided learner engagement, achieved instructional objectives, and enhanced the effectiveness and efficiency of dissection education." In a controlled

Valerie A. Lynn is associate librarian/head librarian, email:vag3@psu.edu, Amie Yenser is senior instructor of Biology, email: alv10@psu.edu, and Ron Harman is library supervisor and technology liaison at The Pennsylvania State University-Hazleton, email: rrh13@ psu.edu

@ 2015 Valerie A. Lynn, Amie Yenser, and Ron Harman 
experiment, students using iPads during the lab were more engaged and spent less time waiting for instructor clarification. In addition, researchers noted benefits of mobile devices in the anatomy and physiology lab, including the flexibility to move about the classroom for greater ease of comparison between models and images. ${ }^{7}$

Previously, Penn State-Hazleton anatomy and physiology students identified different anatomy structures using CD-ROMs in desktop computers affixed to the end of each lab table along with physical anatomical models. Students found it cumbersome to interact simultaneously with the CD-ROM content and the physical anatomical models.

Instructor use of new mobile technology slightly diminished this problem. The biology instructor used one iPad with realisticlooking 3-D apps of various systems in anatomy and physiology to display images on lab monitors for students. Due to cost constraints, the biology department was unable to provide iPads for student use.

Penn State-Hazleton's library and biology laboratory have a history of collaboration, making physical skeletons and muscle models available to students. This collaboration works extremely well with the models used extensively by anatomy and physiology students. However, there are a limited number of physical skeletons and muscle models for student use, both in the laboratory and on reserve in the library. The ability to provide virtual models via iPads seemed like a natural progression of the existing collaboration.

The main goal of the project was to provide anatomy and physiology students with technology-rich resources that would enable them to participate in class, complete course assignments, and improve exam scores. In order to achieve this, several objectives were established:

- to improve pedagogy in the anatomy and physiology laboratory,

- to improve assessment scores,

- to have students complete a course assignment that required the use of iPads, and
- to provide continued support of the technology (iPads and apps).

\section{Moving forward with the collaboration}

To fund the project, the authors applied for and received a National Network of Libraries of Medicine (NN/LM) medical library project award. iPads and health sciences apps (3D Medical: Muscle System Pro III and Skeleton System Pro III) were purchased for the start of the fall 2013 anatomy courses. A recharging and reimaging cart, iPad covers, and carrying cases to protect the iPads were also purchased. ${ }^{8}$ A total of 20 iPads were purchased: 12 iPads reside in the biology laboratory for in-class use, and 8 in the library for 24-hour checkout. When in use in the lab, iPads are protected by Ziploc bags. ${ }^{9}$ The library technology liaison coordinated the procurement of equipment and installation of the apps.

iPad usage occurred on a regular basis in the laboratory with students working in groups of two. During the first lab session the biology instructor demonstrated app features, while students followed on their iPads. Subsequent lab sessions included the discussion and demonstration of library electronic resources available on the iPad via the lab Wi-Fi connection.

Students used the skeletal and muscular apps to assist in the identification of bones and muscles in addition to the actions and attachments of muscles. The apps also gave students the ability to virtually dissect the body like no other CD-ROM program used in classroom instruction. The apps provided a $360^{\circ}$ view of the systems under study. Students made cuts to the models with the swipe of a finger and removed muscles layer by layer to view deeper structures. iPad app images and physical anatomical models were easily viewed simultaneously.

An added advantage of making iPads available was the use of iMovie by students to create short video clips of physical laboratory models, bones, and exercises. Students sculpted a clay muscle model 
then used the iPads to create a video of their models. One group member filmed, while others pointed out and identified the muscles. The video clips were loaded to a private YouTube channel for the course, which allowed them to review the content virtually without the constraints of lab or library hours.

\section{Project assessment}

Success of the iPad project was evaluated using measurable outcomes based on the original four objectives. Quantitative and qualitative metrics used to evaluate these objectives gave the librarian and biology instructor assessment data along with infor-

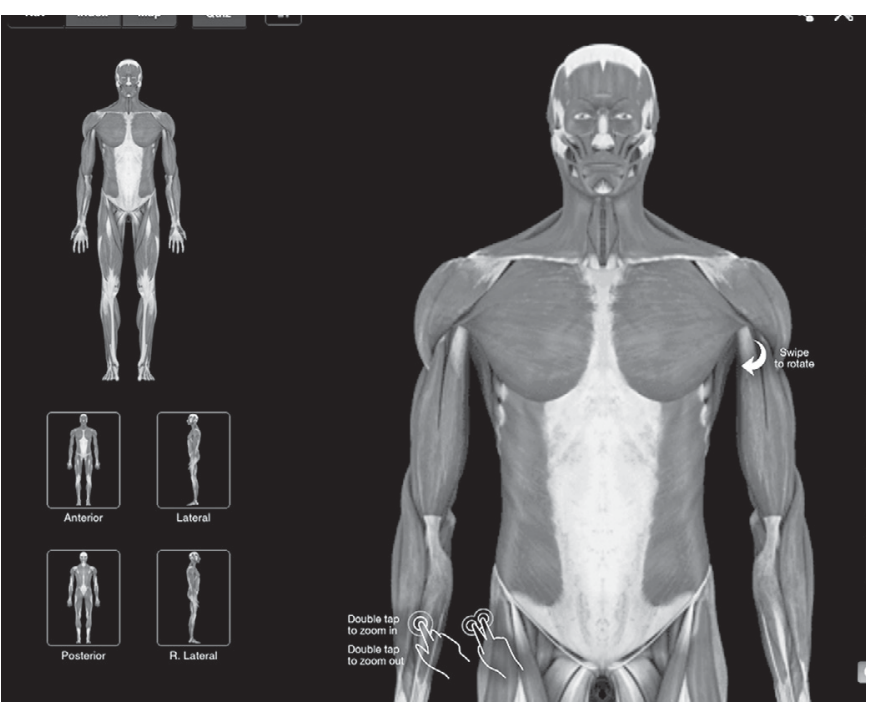

Screenshot of the 3D Medical: Muscle System Pro III app. of each muscle in comparison with deep and superficial muscles using the layering function of the Muscular Pro app. The app clearly indicated the origins and insertions allowing for precise placement of their clay versions on the skeletal models. iPad usage also increased student interaction. Two students shared the same iPad, thus preventing them from working alone during the lab period.

Results from the quantitative student mation for future planning purposes. Quantitative measures included a student survey, course assignment, and exam scores, whereas qualitative measures comprised the biology instructor's written observations during lab sessions.

The first objective was to improve pedagogy in the anatomy and physiology laboratory. It was noted in the instructor's qualitative analysis that use of iPads in the classroom enhanced the student learning experience by allowing them to view images from iPad apps to compare the physical bones during the skeletal system labs. Students rotated bone images in three dimensions to help them see a more full view of each bone.

For the muscular system, the iPad assisted students in identifying the detailed location
$\mathrm{iPad}$, and 52 percent stated that iPad apps made it easier to study for exams. Finally, 65 percent of students believed the iPad video assignment helped them learn the material in the lab. Student comments include:

The video assignment helped by having the group know the locations of each muscle before recording actually began. In a way it 'forced' us to know what we were talking about.

The iPads were a great way to study the lab material when I couldn't get into the lab. It gave me hands on learning without being in the lab.

I found the video assignment both fun and helpful. It was an interesting 
way to combine hands-on work and memorization.

The second objective was to improve assessment scores. The first and second exam scores were compared with those from the last four years. There was not a significant improvement between 2013 and previous years. In fact, there was a slight decrease in exam scores (1.6\% and $1.2 \%$ respectively) between 2012 and 2013. The authors wonder if exam score differences would have been even greater if iPads had not been used.

The third objective was student completion of a course assignment that required the use of iPads. All students successfully completed the video assignment with an average score of $96.4 \%$.

The last objective was to provide continued support of the technology (iPads and apps). The library technology liaison routinely performs updates and the biology instructor continues to seek new relevant apps.

\section{Final thoughts}

Use of iPads and apps by anatomy and physiology students does improve active learning both in and outside the classroom. ${ }^{10}$ The Penn State-Hazleton iPads are now technology de rigueur in the anatomy and physiology courses and in the library. Based on the results of the student iPad usage survey, many students believe the iPad to be an excellent tool to enhance learning in anatomy and physiology courses. In addition, several student comments influenced future design of the course. The biology instructor will require students to explain the functions of the muscles in addition to the location during filming of the video, and zoom in more closely on the muscles.

The outcomes of this successful collaboration include: improved in-classroom pedagogy, 100\% completion of the course assignment, and ongoing support of the iPad project from the Penn State-Hazleton Library and Biology Laboratory. We did not encounter any major challenges or setbacks during the project and would encourage other universities with similar courses to embrace the use of iPads. The successful implementation of the technology coupled with the enthusiastic student response and documented improvement to pedagogy and learning helped meet Penn State-Hazleton's goal of being student-centered by providing excellent educational experiences.

\section{Notes}

1. Daniel Low and M. Goos, "Using an Apple iPad to assist fibreoptic intubation," Anaesthesia 68 no.1 (2013):110-1.

2. Amir Sadri, Adrian D. Murphy, and Joy Odili, "iPad local flap pre-operative planning: A good training tool," Journal of Plastic, Reconstructive \& Aesthetic Surgery 65 no.12 (2012): 1746.

3. Katrina Haynes, "The iPad comes to the school nurse's office," NASN School Nurse 27 no.6 (2012):304-5.

4. June Levine, Randi L. Wolf, Courtney Chinn, and Berton L. Edelstein, "MySmileBuddy: An iPad-based interactive program to assess dietary risk for early childhood caries," Journal of the Academy of Nutrition and Dietetics 112 no. 10 (2012):1539-42.

5. Aiham C. Korbage and Harprit S. Bedi, "The iPad in radiology resident education," Journal of the American College of Radiology 9 no.10 (2012):759-60.

6. Chandler H. Mayfield, Peter T. Ohara, and Patricia S. O'Sullivan, "Perceptions of a mobile technology on learning strategies in the anatomy laboratory," Anatomical Sciences Education 6 no.1 (2013):81-9.

7. Ibid.

8. Sara Q. Thompson, "Setting up a library iPad program: guidelines for success," CERL News 72 no.4 (2011):212-236.

9. Mayfield, Ohara, O'Sullivan, "Perceptions of a mobile technology on learning strategies in the anatomy laboratory," 81-9.

10. Sara Marceglia, Stefano Bonacina, Vittorio Zaccaria, Claudia Pagliari, and Francesco Pinciroli, "How might the iPad change healthcare?" Journal of the Royal Society of Medicine 105 no.6 (2012):233-41. n 